\title{
Alterações anatômicas do limbo foliar de Plantas de Polygonum lapathifolium SuBMETIdAs À APLICAÇÃo DE HERBICIDAS ${ }^{1}$
}

\author{
Anatomical Changes in Polygonum lapathifolium Leaf Blade Submitted to Herbicide \\ Application
}

\author{
COSTA, N.V. ${ }^{2}$, MARTINS, D. ${ }^{3}$, RODELLA, R.A. ${ }^{4}$ e RODRIGUES-COSTA, A.C.P. ${ }^{5}$
}

\begin{abstract}
RESUMO - O presente trabalho teve por objetivo avaliar a eficiência do controle dos herbicidas 2,4-D, diquat e glyphosate e as alterações anatômicas do limbo foliar provocadas por eles em plantas de Polygonum lapathifolium. As plantas foram cultivadas em caixas-d'água sob condições de campo e, quando atingiram seu pleno desenvolvimento (antes do florescimento), pulverizadas com os herbicidas. Avaliaram-se quantitativamente as seguintes características anatômicas da nervura central e internervural das folhas: porcentagem da epiderme adaxial e abaxial, porcentagem da bainha do feixe, porcentagem do feixe vascular, porcentagem de esclerênquima e colênquima, porcentagem de parênquima paliçádico e lacunoso, bem como a espessura foliar $(\mu \mathrm{m})$. Os tratamentos químicos foram: diquat ( $400 \mathrm{~g}$ i.a. ha ${ }^{-1}$ do produto comercial Reward), 2,4-D (1.340 g e.a. ha-1 do produto comercial DMA 806 BR) e glyphosate (4.320 g e.a. ha ${ }^{-1}$ do produto comercial Rodeo) com a adição do surfatante Silwet L-77 a $0,01 \% \mathrm{v} \mathrm{v}^{-1}$. Os principais caracteres anatômicos quantitativos da região da nervura central do limbo foliar que sofreram alterações após a aplicação dos herbicidas foram a porcentagem da epiderme adaxial, a porcentagem de feixe vascular, a porcentagem de colênquima, a porcentagem de parênquima paliçádico e lacunoso e a espessura foliar. Para a região internervural do limbo foliar, os principais caracteres anatômicos quantitativos que sofreram alterações após a aplicação dos herbicidas foram a porcentagem da epiderme adaxial, a porcentagem da bainha do feixe e a espessura foliar. Os herbicidas diquat e 2,4-D foram ineficientes no controle das plantas de P. lapathifolium; o glyphosate apresentou controle superior a 90\% das plantas aos 100 dias após a aplicação. Entretanto, todos os herbicidas permitiram rebrota das plantas.
\end{abstract}

Palavras-chave: anatomia foliar, planta aquática, planta daninha, controle químico.

\begin{abstract}
The aim of this research was to evaluate the efficacy of some herbicides (2, 4-D, diquat, and glyphosate) and the leaf blade anatomic changes such herbicides caused in Polygonum lapathifolium. The plants were cultivated in reservoirs containing water under field conditions and were sprayed with herbicide when reaching full development (before flowering). The following anatomical characteristics were quantitatively evaluated from the central nervure regions and the leaf inter nervural blade: adaxial and abaxial epidermis percentage, bundle sheath percentage, vascular bundle percentage, sclerenchyma and colenchyma percentage, palisade and lacuna parenchyma percentage and leaf thickness $(\mu \mathrm{m})$. The following treatments were carried out: diquat (400 g a.i. ha-1 - Reward), 2, 4-D (1.340 g a.e. ha-1 - DMA 806 BR) and glyphosate (4.320 g a.e. ha - $^{-1}$ Rodeo) with the Silwet $L-77$ surfactant addition at $0.01 \% v v^{-1}$. The main quantitative anatomical region characteristics of the central nervure of the leaflimbus which changed after herbicide application were: adaxial epidermis percentage, vascular bundle percentage, colenchyma percentage, palisade and lacuna parenchyma percentage, and leaf thickness. For the inter-nervural region of the leaf
\end{abstract}

1 Recebido para publicação em 23.8.2010 e na forma revisada em 6.5.2011.

2 Professor Adjunto, UNIOESTE, Caixa Postal 91, 85960-000 Marechal Cândido Rondon-PR, <neumarciovc@hotmail.com>;

${ }^{3}$ Professor Adjunto, Dep. de Produção Vegetal, Faculdade de Ciências Agronômicas, Universidade Estadual Paulista "Júlio de Mesquita Filho" - FCA/UNESP, Fazenda Lageado, Caixa Postal 237, 18603-970 Botucatu-SP; ${ }^{4}$ Professor Adjunto, Dep. de Botânica, Instituto de Biociências de Botucatu, UNESP, Botucatu-SP, ${ }^{5}$ Pós-Doutoranda em Agronomia, UNIOESTE, Marechal Cândido Rondon-PR.

Planta Daninha, Viçosa-MG, v. 29, n. 2, p. 287-294, 2011 
blade, the major quantitative anatomical characters which changed after herbicide application were: adaxial epidermis percentage, bundle sheath percentage, and leafthickness. The herbicides diquat and 2,4-D were inefficient for $\boldsymbol{P}$. lapathifolium plants and glyphosate showed a good control over $90 \%$ at 100 days after application. However, all herbicides allowed plant re-growth.

Keywords: leaf anatomy, aquatic plant, weed, chemical control.

\section{INTRODUÇÃO}

A destruição das matas ciliares e a emissão de diferentes fontes de efluentes e dejetos (urbano, industrial ou agrícola), que ocorre de maneira intensa e descontrolada na maioria dos ambientes aquáticos, causam desequilíbrios no desenvolvimento das comunidades de plantas aquáticas, ocasionados pelo consequente processo de eutrofização (aumento da concentração de nutrientes, especialmente fósforo e nitrogênio, nos ecossistemas aquáticos), que tem como consequência o aumento de sua produtividade (Sheffield, 1970; Esteves, 1998). O desenvolvimento excessivo dessas plantas pode ocasionar vários inconvenientes com relação ao transporte hidroviário, à pesca, à produção de energia, ao abastecimento de água, aos esportes náuticos, à proliferação de vetores de doenças, entre outros.

Dentre as várias espécies que proliferam nos reservatórios das usinas hidrelétricas do Estado de São Paulo, destaca-se em importância Polygonum lapathifolium, que, de acordo com Kissmann \& Groth (2000), é originária da Europa, comum na América do Norte, Uruguai e Argentina. Pode-se comportar como planta anual ou perene e apresenta reprodução por sementes ou por multiplicação vegetativa.

Essa espécie já está se tornando problemática em reservatórios hidrelétricos e em outros tipos de reservatórios, devido à sua grande capacidade de reprodução e produção de biomassa. O método de manejo mais difundido e que melhor tem conciliado a eficiência e custo de controle de plantas daninhas aquáticas nos EUA é a utilização dos herbicidas 2,4$\mathrm{D}$, glyphosate e diquat, que são registrados para o uso em ambientes aquáticos (Cardoso, 2000; Antuniasi et al., 2002).

O controle químico pode apresentar-se altamente seletivo às plantas daninhas aquáticas, além de evitar danos à fauna aquática através da coleta indesejada de insetos e alevinos, como ocorre no controle mecânico. $\mathrm{O}$ uso de herbicidas no controle de plantas daninhas aquáticas apresenta-se como uma excelente alternativa de manejo, uma vez que eles podem promover resultados rápidos de controle, além de manterem a população de plantas daninhas aquáticas em niveis que não prejudiquem o uso múltiplo da água. Entretanto, a eficácia do controle químico está relacionada a diversos fatores, dentre os quais as características da planta destacam-se como variável importante, sendo atualmente pouco estudada (Procópio et al., 2003).

Segundo Ferreira et al. (2002a, b) e Procópio et al. (2003), o estudo anatômico de folhas pode melhorar o entendimento sobre as barreiras que cada espécie impõe à penetração dos herbicidas e, assim, fornecer subsidios para a busca de estratégias que superem esses obstáculos. Dessa forma, a análise anatômica foliar pode ser aplicada com sucesso na identificação de espécies suscetiveis, tolerantes ou resistentes a determinado produto químico, bem como na descrição dos sintomas fitotóxicos, contribuindo com os estudos de seletividade de herbicidas a espécies terrestres ou aquáticas.

No entanto, apesar da importância que representam os recursos hídricos para o Brasil na produção de energia elétrica, na atividade pesqueira e no turismo, por exemplo, existem poucas informações na literatura sobre as comunidades vegetais presentes nos reservatórios, bem como sobre a eficiência dos herbicidas no controle das espécies de plantas aquáticas.

O presente trabalho teve por objetivo avaliar os herbicidas 2,4-D, diquat e glyphosate no controle de plantas de P. lapathifolium e as alterações anatômicas do limbo foliar provocadas pelos produtos.

\section{MATERIAL E MÉTODOS}

O experimento foi conduzido no Núcleo de Pesquisas Avançadas em Matologia - NUPAM, 
do Departamento de Produção Vegetal, pertencente à Faculdade de Ciências Agronômicas de Botucatu/UNESP, e no Departamento de Botânica do Instituto de Biociências de Botucatu/UNESP. O local do experimento apresenta as seguintes coordenadas geográficas: latitude de $22^{\circ} 07^{\prime} 56^{\prime \prime}$ 'S, longitude de $74^{\circ} 66^{\prime} 84^{\prime \prime} \mathrm{W}$ Gr. e altitude de $762 \mathrm{~m}$.

Foram avaliadas plantas de Polygonum lapathifolium, coletadas nos reservatórios do complexo CESP do Estado de São Paulo, as quais foram reproduzidas por meio de suas estruturas de dispersão vegetativa e acondicionadas em pleno sol, em caixas-d’água de fibra de vidro de 350 litros, contendo uma camada de $30 \mathrm{~cm}$ de solo no fundo.

Os herbicidas foram aplicados em pósemergência, quando as plantas atingiram pleno desenvolvimento (antes do florescimento), utilizando-se um pulverizador costal, pressurizado por $\mathrm{CO}_{2}$ e equipado com um reservatório de 2 litros. O equipamento foi regulado para proporcionar um consumo de calda de $200 \mathrm{~L} \mathrm{ha}^{-1}$. A barra de aplicação foi equipada com dois bicos tipo jato plano Teejet XR 110.02, distanciados $50 \mathrm{~cm}$ entre si.

No preparo das soluções foram utilizados os herbicidas diquat (400 g i.a. ha-1 do produto comercial Reward), 2,4-D (1.340 g e.a. ha-1 do produto comercial DMA $806 \mathrm{BR}$ ) e glyphosate (4.320 g e.a. ha ${ }^{-1}$ do produto comercial Rodeo), com a adição do surfatante Silwet L-77, na concentração do produto comercial de $0,01 \% \mathrm{v} \mathrm{v}^{-1}$. Foram realizadas avaliações de controle aos 1, 5, 10, 20, 40, 60 e 100 dias após a aplicação (DAA) dos produtos.

As avaliações de controle foram visuais, por meio de uma escala percentual de notas, em que 0 (zero) corresponde a nenhuma injúria demonstrada pela planta e 100 à morte das plantas, de acordo com a metodologia proposta pela Sociedade Brasileira da Ciência das Plantas Daninhas - SBCPD (1995). Os parâmetros utilizados no estabelecimento das notas foram: quantidade de plantas mortas, inibição do crescimento, quantidade e uniformidade das injúrias e capacidade de rebrota das plantas.

Para os estudos anatômicos foram coletadas, no primeiro e aos $30 \mathrm{DAA}$, porções da região mediana do limbo foliar das plantas que apresentaram sintomas externos de intoxicação e da testemunha. Foram tomadas as porções do terço médio do limbo foliar, compreendendo as regiões da nervura central e da internervural (situada entre a nervura central e o bordo do limbo foliar), fixando-as em FAA 50 (formaldeído + ácido acético glacial + álcool $50 \%$ ) durante 48 horas, sendo, posteriormente, conservadas em álcool 70\% (Johansen, 1940), utilizando-se quatro repetições.

As amostras do material foliar foram desidratadas em série etílica ascendente e, em seguida, infiltradas em resina glicol-metacrilato, seguindo-se a técnica de Gerrits (1991). Realizaram-se cortes transversais com espessura de 8 a $10 \mu \mathrm{m}$, utilizando micrótomo rotatório; os cortes foram submetidos à coloração com azul de toluidina 0,05\% (O'Brien et al., 1964) e montados em resina sintética.

Para a quantificação das estruturas anatômicas das regiões da nervura central e da internervural do limbo foliar, os limites e os contornos dos tecidos foram desenhados com o auxílio de microscópio de projeção, e as mensurações, feitas com auxílio de mesa digitalizadora acoplada a um computador equipado com o programa de Sistema de Planimetria (SPLAN), desenvolvido pelo CINAG - UNESP.

Foram avaliadas as seguintes características anatômicas quantitativas das regiões da nervura central e da internervural do limbo foliar: porcentagem da epiderme adaxial e abaxial, porcentagem da bainha do feixe, porcentagem do feixe vascular, porcentagem de esclerênquima, porcentagem de colênquima, porcentagem de parênquima paliçádico e lacunoso, bem como a espessura foliar $(\mu \mathrm{m})$.

Os tratamentos foram dispostos em um delineamento experimental inteiramente casualizado; para as avaliações das alterações anatômicas do limbo foliar foi utilizado esquema fatorial $4 \times 2$ (4 herbicidas $\times 2$ épocas de avaliações), com quatro repetições. Os dados de controle e das alterações anatômicas do limbo foliar foram analisados estatisticamente, empregando-se o teste LSD a 5\% de probabilidade; os dados originais, expressos em porcentagem, foram transformados utilizando-se arco seno $\sqrt{ } \mathrm{x} / 100$ (Pimentel-Gomes, 1976). 


\section{RESULTADOS E DISCUSSÃO}

Na Tabela 1 são apresentados os valores da porcentagem de controle proporcionado pelos herbicidas diquat, 2,4-D e glyphosate em plantas de P. lapathifolium. Verificou-se que, a partir de $1 \mathrm{DAA}$, o herbicida diquat promoveu $63,8 \%$ de controle das plantas em relação à testemunha. Entretanto, aos 30 DAA apenas o glyphosate apresentou controle acima de $95 \%$. É importante ressaltar que a partir de 5, 30 e 40 DAA as plantas dos tratamentos com os herbicidas diquat, 2,4-D e glyphosate apresentaram rebrota, respectivamente.

Dessa forma, esse fato evidencia que, apesar da elevada eficiência apresentada pelo glyphosate no controle de $P$. lapathifolium e de os brotos apresentarem desenvolvimento pouco vigoroso, com sintomas de clorose e atrofiamento do limbo foliar, torna-se importante a realização de monitoramento constante nas áreas aplicadas, para que se possa avaliar a necessidade de uma reaplicação e evitar a reinfestação do local.

Contudo, esses resultados corroboram os obtidos por Terra et al. (2003), que avaliaram os efeitos dos herbicidas diquat (480 g i.a. ha ${ }^{-1}$ ), 2,4-D (720 a 1.440 g e.a. ha- $\left.{ }^{-1}\right)$ e glyphosate (2.400 e 3.360 g e.a. ha ${ }^{-1}$ Aterbane $0,5 \% \mathrm{v} \mathrm{v} \mathrm{v}^{-1}$ ) no controle de P. lapathifolium; apenas o herbicida glyphosate, independentemente da dose utilizada, controlou as plantas, atingindo $100 \%$ aos 46 dias após a aplicação.

Inicialmente, o herbicida diquat, assim como o 2,4-D, promoveu injúrias severas; entretanto, no decorrer do período das avaliações, elas se dissiparam e as plantas rebrotaram. Na Tabela 2 estão apresentados os valores do teste $\mathrm{F}$ e do coeficiente de variação dos caracteres anatômicos quantitativos da região da nervura central e internervural do limbo foliar de plantas de P. lapathifolium.

Na Tabela 3 podem-se verificar os valores médios dos caracteres anatômicos quantitativos da região da nervura central do limbo foliar das plantas de P. lapathifolium. Observa-se que apenas os caracteres de porcentagem da epiderme abaxial, porcentagem da bainha do feixe, porcentagem de esclerênquima e porcentagem de colênquima não apresentaram interação entre os fatores herbicidas e época de avaliação. Assim, ao analisar as médias obtidas pelos herbicidas 2,4-D e glyphosate para o caractere porcentagem da epiderme adaxial, observou-se que houve redução de 50,2 e 42,2\%, respectivamente, em relação à testemunha aos 30 DAA.

Apenas o 2,4-D apresentou redução de $40,7 \%$ aos 30 DAA em relação à primeira época de avaliação. Quanto à porcentagem de feixe vascular, constatou-se o maior valor médio para o herbicida diquat em relação aos demais tratamentos já após 1 DAA, o que não está de acordo com o modo de ação do herbicida.

$\mathrm{O}$ aumento da porcentagem de esclerênquima aos $30 \mathrm{DAA}$ em relação à primeira avaliação pode ser devido à maior deposição de lignina nas paredes da célula no decorrer do período. Para a porcentagem de colênquima, verificou-se redução média de 37,2 e $38,2 \%$ para o $2,4-\mathrm{D}$ e o glyphosate, respectivamente, em comparação com a

Tabela 1 - Porcentagem de controle das plantas de P. lapathifolium após aplicação dos herbicidas. Botucatu-SP, 2005

\begin{tabular}{|c|c|c|c|c|c|c|c|c|}
\hline \multirow{2}{*}{ Tratamento } & \multirow{2}{*}{$\begin{array}{c}\text { Dose } \\
\text { (i.a. } \text { g ha }^{-1} \text { ) }\end{array}$} & \multicolumn{7}{|c|}{ Dias após a aplicação } \\
\hline & & 1 & 5 & 10 & 30 & 40 & 60 & 100 \\
\hline Testemunha & --- & $0,0 \mathrm{c}$ & $0,0 \mathrm{c}$ & $0,0 \mathrm{c}$ & $0,0 \mathrm{~b}$ & $0,0 \mathrm{c}$ & $0,0 \mathrm{c}$ & $0,0 \mathrm{c}$ \\
\hline Diquat & $400^{*}$ & $63,8 \mathrm{a}$ & $28,8 \mathrm{a}$ & $0,0 \mathrm{~b}$ & $0,0 \mathrm{~b}$ & $0,0 \mathrm{c}$ & $0,0 \mathrm{c}$ & $0,0 \mathrm{c}$ \\
\hline $2,4-\mathrm{D}$ & 1.340 & $18,8 \mathrm{~b}$ & $33,8 \mathrm{~b}$ & $62,5 \mathrm{a}$ & $72,5 \mathrm{a}$ & $48,8 \mathrm{~b}$ & $45,0 \mathrm{~b}$ & $45,0 \mathrm{~b}$ \\
\hline Glyphosate + Silwet L-77 & $4.320 *+0,01 \mathrm{v} \mathrm{v}^{-1}$ & $0,0 \mathrm{c}$ & $25,0 \mathrm{~b}$ & $68,3 \mathrm{a}$ & $95,5 \mathrm{a}$ & $94,8 \mathrm{a}$ & $97,2 \mathrm{a}$ & $94,0 \mathrm{a}$ \\
\hline \multicolumn{2}{|c|}{$\mathrm{F}_{\text {Tratamento }}$} & $379,886^{* *}$ & $115,623 * *$ & $203,334 * *$ & $55,582 * *$ & $16,526 * *$ & $17,615^{* *}$ & $15,778^{* *}$ \\
\hline \multicolumn{2}{|c|}{$\mathrm{CV}(\%)$} & 12,67 & 13,37 & 10,22 & 31,32 & 60,76 & 60,22 & 62,89 \\
\hline \multicolumn{2}{|c|}{ DMS } & 3,408 & 5,821 & 5,531 & 16,976 & 28,329 & 28,481 & 28,788 \\
\hline
\end{tabular}

Os dados originais de porcentagem foram transformados em arco seno $\sqrt{\mathrm{x}} / 100$. Médias seguidas de mesma letra, minúsculas na coluna, não diferem estatisticamente entre si a $5 \%$ de probabilidade pelo teste LSD. ${ }^{* *}$ significativo a $1 \%$ de probabilidade. ${ }^{*}$ equivalente ácido. 
Tabela 2 - Valores do teste F e do coeficiente de variação dos caracteres anatômicos quantitativos da região da nervura central e internervural do limbo foliar das plantas de P. lapathifolium. Botucatu-SP, 2005

\begin{tabular}{|c|c|c|c|c|}
\hline Fonte de variação & Herbicida & Avaliação & Herbicida $\mathrm{x}$ avaliação & $\mathrm{CV}(\%)$ \\
\hline & \multicolumn{4}{|c|}{ Região da Nervura Central } \\
\hline$\%$ Epiderme Adaxial & $5,430 * *$ & $0,709^{\mathrm{ns}}$ & $0,607^{\mathrm{ns}}$ & 18,38 \\
\hline$\%$ Epiderme Abaxial & $1,228^{\mathrm{ns}}$ & $2,262^{\text {ns }}$ & $0,796^{\mathrm{ns}}$ & 20,28 \\
\hline$\%$ Bainha do feixe & $3,413 *$ & $0,836^{\mathrm{ns}}$ & $1,066^{\mathrm{ns}}$ & 89,88 \\
\hline$\%$ Feixe Vascular & $5,120 *$ & $0,551^{\mathrm{ns}}$ & $2,352^{\mathrm{ns}}$ & 8,61 \\
\hline \% Esclerênquima & $5,649 * *$ & $0,312^{\mathrm{ns}}$ & $2,360^{\mathrm{ns}}$ & 12,87 \\
\hline \% Colênquima & $7,002 * *$ & $0,249^{\mathrm{ns}}$ & $0,259^{\mathrm{ns}}$ & 17,12 \\
\hline \% Parênquima paliçádico & $14,029 * *$ & $0,001^{\mathrm{ns}}$ & $0,614^{\mathrm{ns}}$ & 9,61 \\
\hline \% Parênquima lacunoso & $11,382 * *$ & $0,067^{\mathrm{ns}}$ & $1,582^{\mathrm{ns}}$ & 6,00 \\
\hline \multirow[t]{2}{*}{ Espessura Foliar $(\mu \mathrm{m})$} & $13,171 * *$ & $0,675^{\mathrm{ns}}$ & $2,721^{\mathrm{ns}}$ & 13,84 \\
\hline & \multicolumn{4}{|c|}{ Região Internervural } \\
\hline$\%$ Epiderme Adaxial & $3,230 *$ & $1,037^{\mathrm{ns}}$ & $2,057^{\mathrm{ns}}$ & 6,31 \\
\hline$\%$ Epiderme Abaxial & $0,580^{\mathrm{ns}}$ & $0,945^{\mathrm{ns}}$ & $0,766^{\mathrm{ns}}$ & 11,17 \\
\hline$\%$ Bainha do feixe & $22,848^{* *}$ & $0,018^{\mathrm{ns}}$ & $3,147^{\mathrm{ns}}$ & 30,26 \\
\hline$\%$ Feixe Vascular & $2,215^{\mathrm{ns}}$ & $0,293^{\mathrm{ns}}$ & $0,576^{\mathrm{ns}}$ & 31,22 \\
\hline \% Parênquima paliçádico & $1,027^{\mathrm{ns}}$ & $1,432^{\mathrm{ns}}$ & $0,951^{\mathrm{ns}}$ & 19,36 \\
\hline \% Parênquima lacunoso & $3,067^{*}$ & $1,103^{\mathrm{ns}}$ & $0,279^{\mathrm{ns}}$ & 16,02 \\
\hline Espessura Foliar $(\mu \mathrm{m})$ & $50,420^{* *}$ & $15,268^{* *}$ & $13,836^{* *}$ & 12,99 \\
\hline
\end{tabular}

** significativo a $1 \%$ de probabilidade; * significativo a $5 \%$ de probabilidade; ${ }^{\text {ns }}$ não significativo.

testemunha. Da mesma maneira, o 2,4-D e o glyphosate promoveram redução da porcentagem do parênquima paliçádico, responsável pela fotossintese da planta, em cerca de $45,0 \%$ em relação à testemunha aos 30 DAA.

Comportamento contrário ao descrito anteriormente foi observado considerando o caractere porcentagem de parênquima lacunoso. A redução da espessura da folha provocada pelo diquat após 1 DAA pode ser explicada pela ação rápida de seu mecanismo de ação na planta, desidratando a folha. Contudo, o 2,4-D e o glyphosate promoveram aumento desse caractere aos 30 DAA.

$\mathrm{Na}$ Tabela 4 podem-se observar os valores médios dos caracteres anatômicos quantitativos da região internervural do limbo foliar das plantas de P. lapathifolium. Verificou-se que apenas os caracteres porcentagem da bainha do feixe e espessura foliar apresentaram interação entre os fatores herbicidas e época de avaliação. Para a porcentagem da bainha do feixe a alteração mais significativa foi provocada pelo 2,4-D, que promoveu destruição total desse caractere aos 30 DAA. Contudo, para os valores da espessura foliar houve comportamento contrário ao observado para a região da nervura central: os herbicidas 2,4-D e glyphosate reduziram este caractere em mais de 50,0\% em relação à testemunha, aos 30 DAA.

Segundo Murphy \& Barrett (1990) e Rodrigues \& Almeida (1998), o 2,4-D é idêntico às auxinas (AIA), pois provoca intensa divisão celular no câmbio, endoderme, periciclo e floema, sendo o encurtamento do tecido internervural das folhas e a epinastia os sintomas mais evidentes nas dicotiledôneas. Esse fato pode explicar as alterações observadas nas regiões da nervura central e internervural do limbo foliar das plantas de P. lapathifolium.

É importante ressaltar que no presente trabalho foi observado que, mesmo mostrando controle superior a $90 \%$, a exemplo do glyphosate (Tabela 1), algumas plantas apresentaram início de rebrota. Esse fato pode ser justificado pela grande variabilidade 
Tabela 3 - Valores médios dos caracteres anatômicos quantitativos da região da nervura central do limbo foliar das plantas de P. lapathifolium. Botucatu-SP, 2005

\begin{tabular}{|c|c|c|c|c|c|}
\hline \multirow{2}{*}{$\mathrm{DAA}^{1 /}$} & \multicolumn{5}{|c|}{ Herbicida } \\
\hline & Testemunha & diquat & $2,4-\mathrm{D}$ & glyphosate & Média \\
\hline & \multicolumn{5}{|c|}{$\%$ Epiderme adaxial } \\
\hline 1 & 1,55 & 1,99 & 2,37 & 1,18 & 1,77 \\
\hline 16 & 1,89 & 1,79 & 2,34 & 1,37 & 1,85 \\
\hline \multirow[t]{2}{*}{ Média } & $1,72 \mathrm{a}$ & $1,89 \mathrm{a}$ & $2,355 \mathrm{a}$ & $1,275 \mathrm{~b}$ & 1,81 \\
\hline & \multicolumn{5}{|c|}{$\%$ Epiderme abaxial } \\
\hline 1 & 2,49 & 2,72 & 2,96 & 2,11 & 2,57 \\
\hline 16 & 3,53 & 2,60 & 3,08 & 2,75 & 2,99 \\
\hline \multirow[t]{2}{*}{ Média } & 3,01 & 2,66 & 3,02 & 2,43 & 2,78 \\
\hline & \multicolumn{5}{|c|}{$\%$ Bainha do feixe } \\
\hline 1 & 0,16 & 0,73 & 0,12 & 0,15 & 0,29 \\
\hline 16 & 0,00 & 0,33 & 0,32 & 0,29 & 0,24 \\
\hline \multirow[t]{2}{*}{ Média } & $0,08 \mathrm{~b}$ & $0,53 \mathrm{a}$ & $0,22 \mathrm{~b}$ & $0,22 \mathrm{ab}$ & 0,26 \\
\hline & \multicolumn{5}{|c|}{$\%$ Feixe vascular } \\
\hline 1 & 17,89 & 15,37 & 19,26 & 17,38 & 17,48 \\
\hline 16 & 23,52 & 15,34 & 17,88 & 16,56 & 18,33 \\
\hline \multirow[t]{2}{*}{ Média } & $20,71 \mathrm{a}$ & $15,36 \mathrm{c}$ & $18,57 \mathrm{ab}$ & $16,97 \mathrm{bc}$ & 17,90 \\
\hline & \multicolumn{5}{|c|}{ \% Esclerênquima } \\
\hline 1 & 4,94 & 3,29 & 4,87 & 6,42 & 4,88 \\
\hline 16 & 3,41 & 4,23 & 5,65 & 5,25 & 4,64 \\
\hline \multirow[t]{2}{*}{ Média } & $4,18 \mathrm{bc}$ & $3,76 \mathrm{c}$ & $5,26 \mathrm{ab}$ & $5,84 \mathrm{a}$ & 4,76 \\
\hline & \multicolumn{5}{|c|}{ \% Colênquima } \\
\hline 1 & 7,86 & 7,07 & 12,89 & 5,97 & 8,45 \\
\hline 16 & 8,16 & 7,32 & 10,45 & 5,51 & 7,86 \\
\hline \multirow[t]{2}{*}{ Média } & $8,01 \mathrm{~b}$ & $7,20 \mathrm{~b}$ & $11,67 \mathrm{a}$ & $5,74 \mathrm{~b}$ & 8,15 \\
\hline & \multicolumn{5}{|c|}{ \% Parênquima paliçádico } \\
\hline 1 & 8,11 & 10,32 & 11,00 & 6,01 & 8,86 \\
\hline 16 & 9,44 & 9,32 & 0,62 & 6,02 & 6,35 \\
\hline \multirow[t]{2}{*}{ Média } & $8,78 \mathrm{~b}$ & $9,82 \mathrm{ab}$ & $5,81 \mathrm{a}$ & $6,02 \mathrm{c}$ & 7,61 \\
\hline & \multicolumn{5}{|c|}{ \% Parênquima lacunoso } \\
\hline 1 & 56,99 & 58,51 & 46,59 & 60,78 & 55,72 \\
\hline 16 & 50,04 & 59,08 & 49,67 & 62,25 & 55,26 \\
\hline \multirow[t]{2}{*}{ Média } & $53,52 \mathrm{~b}$ & $58,80 \mathrm{a}$ & $48,13 \mathrm{c}$ & $61,52 \mathrm{a}$ & 55,49 \\
\hline & \multicolumn{5}{|c|}{ Espessura foliar $(\mu \mathrm{m})$} \\
\hline 1 & $2.068,46$ & $2.074,28$ & $1.254,86$ & $1.970,69$ & $1.842,07$ \\
\hline 16 & $1.589,89$ & $2.125,91$ & $1.454,88$ & $7.625,12$ & $3.198,95$ \\
\hline Média & $1.829,18 \mathrm{~b}$ & $2.100,10 \mathrm{a}$ & $1.354,87 \mathrm{c}$ & $4.797,91 \mathrm{ab}$ & $2.520,51$ \\
\hline
\end{tabular}

Os dados originais de porcentagem foram transformados em arco seno $\sqrt{\mathrm{x}} / 100$. Médias seguidas de mesma letra, minúsculas na linha, não diferem estatisticamente entre si a $5 \%$ de probabilidade pelo teste LSD. ํ/ DAA - dias após a aplicação.

genética existente entre as plantas de $P$. lapathifolium, sendo possivel que algumas delas apresentem a capacidade de metabolizar o herbicida após um período longo de tempo e se regenerar. Outro ponto diz respeito ao próprio ambiente aquático, que pode permitir que a planta realize a sua desintoxicação lentamente, por estar sempre saturado de água, mesmo quando são utilizadas doses elevadas de herbicidas. 
Tabela 4 - Valores médios dos caracteres anatômicos quantitativos da região internervural do limbo foliar das plantas de $P$. lapathifolium Botucatu-SP, 2005

\begin{tabular}{|c|c|c|c|c|c|}
\hline \multirow{2}{*}{$\mathrm{DAA}^{\underline{1}}$} & \multicolumn{5}{|c|}{ Herbicida } \\
\hline & Testemunha & diquat & $2,4-\mathrm{D}$ & glyphosate & Média \\
\hline & \multicolumn{5}{|c|}{$\%$ Epiderme adaxial } \\
\hline 1 & 6,84 & 8,35 & 8,15 & 8,26 & 7,90 \\
\hline 16 & 7,87 & 7,23 & 8,66 & 9,25 & 8,25 \\
\hline \multirow[t]{2}{*}{ Média } & $7,36 \mathrm{~b}$ & $7,79 \mathrm{ab}$ & $8,41 \mathrm{a}$ & $8,76 \mathrm{a}$ & 8,08 \\
\hline & \multicolumn{5}{|c|}{$\%$ Epiderme abaxial } \\
\hline 1 & 5,08 & 5,90 & 5,87 & 6,33 & 5,80 \\
\hline 16 & 6,63 & 5,50 & 6,33 & 6,67 & 6,28 \\
\hline \multirow[t]{2}{*}{ Média } & 5,86 & 5,70 & 6,10 & 6,50 & 6,04 \\
\hline & \multicolumn{5}{|c|}{$\%$ Bainha do feixe } \\
\hline 1 & $5,99 \mathrm{a}$ & $7,66 \mathrm{a}$ & $30,30 \mathrm{a}$ & $0,00 \mathrm{~b}$ & 10,99 \\
\hline 16 & $2,89 \mathrm{bc}$ & $6,58 \mathrm{ab}$ & $7,39 \mathrm{a}$ & $2,67 \mathrm{c}$ & 4,88 \\
\hline \multirow[t]{2}{*}{ Média } & 4,44 & 7,12 & 18,85 & 1,34 & 7,94 \\
\hline & \multicolumn{5}{|c|}{$\%$ Feixe vascular } \\
\hline 1 & 1,90 & 2,47 & 1,75 & 4,11 & 2,56 \\
\hline 16 & 2,63 & 1,60 & 2,44 & 4,27 & 2,74 \\
\hline \multirow[t]{2}{*}{ Média } & 2,27 & 2,04 & 2,10 & 4,19 & 2,65 \\
\hline & \multicolumn{5}{|c|}{ \% Parênquima paliçádico } \\
\hline 1 & 44,73 & 41,96 & 51,94 & 48,68 & 46,83 \\
\hline 16 & 41,42 & 44,00 & 49,55 & 35,84 & 42,70 \\
\hline \multirow[t]{2}{*}{ Média } & 43,08 & 42,98 & 50,75 & 42,26 & 44,77 \\
\hline & \multicolumn{5}{|c|}{ \% Parênquima lacunoso } \\
\hline 1 & 35,47 & 33,66 & 24,71 & 32,61 & 31,61 \\
\hline 16 & 38,56 & 35,10 & 25,64 & 165,21 & 66,13 \\
\hline \multirow[t]{2}{*}{ Média } & $37,02 \mathrm{a}$ & $34,38 \mathrm{a}$ & $25,18 \mathrm{~b}$ & $98,91 \mathrm{a}$ & 48,87 \\
\hline & \multicolumn{5}{|c|}{ Espessura foliar $(\mu \mathrm{m})$} \\
\hline 1 & $398,16 \mathrm{aA}$ & $394,41 \mathrm{aA}$ & $343,56 \mathrm{aA}$ & $163,52 \mathrm{bA}$ & 324,91 \\
\hline 16 & $192,16 \mathrm{bB}$ & $383,58 \mathrm{aA}$ & $345,11 \mathrm{aA}$ & $164,84 \mathrm{bA}$ & 271,42 \\
\hline Média & 295,16 & 389,00 & 344,34 & 164,18 & 298,17 \\
\hline
\end{tabular}

Os dados originais de porcentagem foram transformados em arco seno $\sqrt{\mathrm{x}} / 100$. Médias seguidas de mesma letra, minúsculas na linha $\mathrm{e}$ maiúscula na coluna, não diferem estatisticamente entre si a $5 \%$ de probabilidade pelo teste LSD. $\stackrel{1}{1}^{2}$ DAA - dias após a aplicação.

Com base nos resultados obtidos, ressaltase que os principais caracteres anatômicos quantitativos da região da nervura central do limbo foliar que sofreram alterações após a aplicação dos herbicidas foram: porcentagem da epiderme adaxial, porcentagem de feixe vascular, porcentagem de colênquima, porcentagem de parênquima paliçádico e lacunoso e espessura foliar.

Em se tratando da região internervural do limbo foliar, os principais caracteres anatômicos quantitativos que sofreram alterações após a aplicação dos herbicidas foram a porcentagem da epiderme adaxial, a porcentagem da bainha do feixe e a espessura foliar. As alterações mais evidentes foram observadas na segunda época de avaliação (30 DAA). Esses resultados evidenciam que o manejo químico de plantas de $P$. lapathifolium requer mais estudos de longo prazo, uma vez que essa espécie apresenta alta capacidade de regeneração e reprodução após a aplicação de herbicidas considerados eficientes, como o 
glyphosate. Contudo, estudos morfológicos, sobretudo referentes à anatomia foliar de plantas aquáticas e correlacionados com eficiência de herbicidas, são bastante escassos no Brasil, devendo ser realizados mais frequentemente.

\section{LITERATURA CITADA}

ANTUNIASSI, U. R.; VELINI, E. D.; MARTINS, D. Remoção mecânica de plantas aquáticas: Análise econômica e operacional. Planta Daninha, v. 20, n. 1, p. 35-43, 2002. (Edição Especial)

CARDOSO, L. R. Controle químico de diferentes acessos de aguapé (Eichhornia crassipes). Caracterização através de eletroforese (RAPD). 2000. 93 f. Dissertação (Mestrado em Ciências Agronômicas) - Faculdade de Ciências Agronômicas, Universidade Estadual de Paulista, Botucatu, 2000 .

ESTEVES, F. A. Fundamentos de limnologia. 2.ed. Rio de Janeiro: Interciência, 1998. 602 p

FERREIRA, E. A. et al. Estudos anatômicos de folhas de plantas daninhas. I. Nicandra physaloides, Solanum americanum e Raphanus raphanistrum. Planta Daninha, v. 20 , n. 2 , p. $159-167,2002 \mathrm{a}$.

FERREIRA, E. A. et al. Estudos anatômicos de folhas de plantas daninhas. II. Bidens pilosa, Emilia sonchifolia, Agerantum conyzoides e Sonchus asper. Planta Daninha, v. 20 , n. 3 , p. $327-335,2002 b$.

GERRITS, P. O. The application of glycol metacrylate in histotechnology: same fundamental principles. Germany: Lica Gmgh, 1991. 80 p.
HOFSTRA, D. E.; CLAYTON, J. S.; GETSINGER, K. D Evaluation of selected herbicides for the control of exotic submerged weeds in New Zealand: II. The effects of turbidity on diquat and endothall efficacy. J. Aquat. Plant Manag., v. 39 , v. 1, p. $25-27,2001$.

JOHANSEN, D. A. Plant microtechnique. New York: McGrow-Hill Book, 1940. 523 p.

KISSMANN, K. G; GROTH, D. Plantas infestantes e nocivas. 2.ed. São Paulo: BASF, 2000. Tomo III. 724 p.

O`BRIEN, T. P.; FEDER, N.; McCULLY, M. E. Polychmofic staing of plant cellular wall by toluidine blue. Protoplasma, v. 59 , p. $368-373,1964$

PIMENTEL-GOMES, F. Curso de estatística experimental. 6.ed. Piracicaba: Gráfica Binetti, 1976. 430 p.

PROCÓPIO, S. O. et al. Estudos anatômicos de folhas de plantas daninhas de grande ocorrência no Brasil. III. Galinsoga parviflora, Crotalaria incana, Conyza bonariensis e Ipomoea cairica. Planta Daninha, v. 21, n. 1, p. 1-9, 2003.

RODRIGUES, B. N.; ALMEIDA, F. S. Guia de herbicidas. 4.ed. Londrina, 1998. 648 p.

SHEFFIELD, C. W. Eutrophication and aquatic weeds Hyacinth Control J., v. 8, n. 2, p. 26-28, 1970.

SOCIEDADE BRASILEIRA DA CIÊNCIA DAS PLANTAS DANINHAS - SBCPD. Procedimentos para instalação, avaliação e análise de experimentos com herbicidas. Londrina: 1995. $42 \mathrm{p}$

TERRA M. A. et al. Controle químico de plantas aquáticas: Polygonum lapathifolium. Planta Daninha, v. 21, p. 85-88, 2003. (Edição Especial) 